\title{
Relation between Stress Conditions, Uncertainty and Incongruity Intolerance, Rigidity and Mental Health: Experimental Demonstrations
}

\author{
Valeria Biasi' ${ }^{1}$, Paolo Bonaiuto², James M. Levin ${ }^{3}$ \\ ${ }^{1}$ Department of Education, "Roma Tre" University, Rome, Italy \\ ${ }^{2}$ Department of Psychology, "Sapienza" University of Rome, Rome, Italy \\ ${ }^{3}$ John Jay College, City University of New York, New York, USA \\ Email: valeria.biasi@romascuola.net, paolo.bonaiuto@uniroma1.it, jameslevin@msn.com
}

Received 9 November 2014; accepted 17 December 2014; published 14 January 2015

Copyright (C) 2015 by authors and Scientific Research Publishing Inc.

This work is licensed under the Creative Commons Attribution International License (CC BY). http://creativecommons.org/licenses/by/4.0/

(c) (i) Open Access

\section{Abstract}

An innovative critique of existing studies on creativity has revealed the opportunity of distinguishing among different varieties of creative tasks, and namely creativity for "Continuity", "Opposition" and "Detachment", considering relations between products and perceived models. This theoretical contribution has led to a specific evaluation procedure: the COD Creativity test. Considering the influences of dynamic processes on creative processes, it is worth experimentally studying the effects of short-term stress or comfort treatments. The similarities and differences among various existing studies are examined. A non-invasive but effective procedure, compared to classic techniques, is described: the "drawing recall" of stressful or relaxing real experiences, accompanied by detailed evaluations of the emotional sphere. In a specific investigation, creativity turned out to be significantly lower after acute stress with respect to comfort treatment. In conclusion, the cognitive, decisional and activity processes involved in creativity operations can be considered as strictly reflecting emotional dynamic processes, as well as the experiences gained during the stress or comfort treatments. Results are explained considering the role of conflict overload in stress as a factor of incongruity and uncertainty intolerance, inhibiting the production of bizarre and unusual ideas and configurations, and thus reducing essential aspects relevant to the evaluation of creativity levels. From clinical point of view, we underline that decades of research has generally shown that being more rigid is associated with poorer mental health. Our experimental study gives confirmation of the link between stress and intolerance of uncertainty and incongruity; this correlation could augment the negative impact of stressors on anxiety levels. In summary, people with high level of intolerance of uncertainty and, generally, with high level of intolerance of incongruity, develop mental rigidity, and this traits constellation represent a risk for mental 
health.

Keywords

Creativity, Uncertainty and Incongruity Intolerance, Mental Health, Rigidity, Stress

\section{Introduction}

The concept and term "creativity" has seen widespread use in psychological disciplines for about fifty years, mainly following works by Guilford [1]-[6]. These have contributed to the distinction between "convergent" activities, geared to establishing and solving closed problems demanding the choice of a single correct answer, and the typically creative, or "divergent", activities, that can put together as many answers as possible to open problems. The following characteristics have been considered the attributes of creativity: novelty, originality, anticonventionality, but also appropriateness and functionality with respect to value systems, so as to deserve suitable acknowledgements, at least in the long run. In this regard, several theoretical and empirical research lines have developed, which have seen the work of Gestaltists like Wertheimer and Dunker, cognitivists like Gardner, Finke and Sternberg, psychoanalysts and dynamic psychologists from Freud, Jung and Klein to Winnicott, Kris and Arieti; psychometricians like Cattell, the already mentioned Guilford, and Torrance; experimental psychologists and personality researchers like Bartlett, Barron, Eysenck and Csikszentmihalyi [7]-[15].

As regards the present contribution, our interest mainly focuses on the relations between graphic creativity and the psychological dynamics coming into play when people find themselves in stressful conditions or, the opposite, in conditions of comfort. These can also easily involve problem-solving skills, of both a convergent and divergent kind. In this regard, a rich theoretical debate has developed in the international literature, with the support of experimental studies or systematic observations: in particular, on how short-term stress or comfort states can affect creative performances. It is possible to find theoretical positions and empirical results on this, obtained with different procedures that show reciprocal similarities but also considerable discrepancies.

One of the first investigations was published by Leith [16], who had examined German children of 9, 11 and 13 years of age (both genders) involved in verbal creative performances under conditions of moderate stress (requesting performances with injunctions to "do your best", avoiding delay, and so on). The other condition was to carry out the same performances in a quiet and relaxed atmosphere. The moderate stress tended to induce higher verbal creativity scores (number and originality of responses), at all age levels, than the relaxed conditions. Note that Leith's participants were all in the so-called "latency age", which is known to be a period of conformity to norms and injunctions by adults.

In laboratory conditions, Martindale and Greenough [17] found worse creative performances after short-term stress treatments, that is, school examination sessions, as opposed to relaxation sessions. Similar results were obtained by Dwral [18]. On the other hand, one must also recall the study by Krampen [19], who obtained improvements in divergent thinking trials following authogenic training and relaxation induced by listening to particular music.

Khasky and Smith [20] experimented with short periods of muscular relaxation, yoga or guided imagination, in comparison with a situation considered "of control" (browsing through magazines for about twenty minutes), and they did not obtain significant effects as regards performances in the Torrance Test of Creative Thinking. We should recall, however, that the latter reactive measures creativity as a trait and may be insensitive to variations in state.

We can also mention contributions by Suedfeld, Metcalfe and Bluck [21], or by Forgays and Forgays [22] [23], who used the "flotation-relaxation" procedure: that is, relaxing for $60 \mathrm{~min}$. while floating in a quiet darkened environment, in a special tank with very salty water (a magnesium sulphate solution). In the latter study a control group was organized, with participants spending 60-min. resting in a couch in a dimly lit room. The Guilford Creativity Scale, consisting of three fluency sub-tests, was used pre- and post-treatment. Comparing the results, floaters increased their creativity score, while controls remained at the same level. Relaxation and other features were also controlled through SPI and POMS scales. The results allowed the experimenters to conclude that, with respect to the controls, flotation-relaxation produces a relaxed but alert state, which may set the stage 
for creativity benefit.

We must also mention some relatively recent studies by Isen, Dabman and Nowicki [24], Kaufmann and Vosburg [25], Vosburg [26], Isen [27] [28], and various others. The first study by Kaufmann and Vosburg [25], and a subsequent study by Vorsburg [26], used pre-existing positive or negative emotional states, assessed with the Russell Adjective Check List [29]. While in the first case the results were contradictory, in the second Vorsburg, on the whole, found positive correlations between positive mood and fluency, and negative correlations between negative emotions and the dependent variable. Isen and co-workers, as well as Kaufmann and Vosburg [25] in another study, instead tried to directly induce positive emotional states, meant as the opposite of negative ones, and possibly conditions of relative emotional neutrality. Procedures of the first kind were, for example, the projections of humorous film sequences, or giving a gift consisting of a packet of candies; while to induce negative states, the subjects could be shown a short film with sad or tragic contents. Control conditions consisted of using films of a neutral emotional tone or, in certain cases, of no administrations whatsoever or of even doing some simple physical exercises. The reaching of positive, negative or neutral affective states was assessed through written self-evaluation procedures. Sometimes, however, no such checks were made, and just taking these effects for granted, on the basis of the previous literature [30]. The creativity trials for these various authors mainly consisted of word association tests with an evaluation of the unusualness of the words thought up; or the request to solve problems of creative reasoning without resorting to the "functional fixation" defined by Duncker [31]. The results again showed contradictions in the case of Kaufmann \& Vosburg; while the other researchers saw, above all, the beneficial effect of practices of positive emotional induction with respect to the other conditions. However, the inverse effects was not obtained, which was hypothesised and sought through the opposite procedure. Therefore, these very same scholars suggested improving the experimental techniques, and we shall return to this in our conclusions.

Interesting results, apparently contrasting with some of the previous findings, were obtained by Simonton [32], in his historiometric investigations of great artists' biographies. These accurate studies demonstrated the prevalent effects of creativity activation in more difficult periods in the lives of these personages; instead of the prevalent effect of inhibition of creative functions, as those sometimes found under experimentally-induced stress in the laboratory. Fundamentally different conditions, such as higher personal giftedness in the great artists, professional engagement and opportunities for re-elaboration of life stress, may explain the differences, as suggested by Biasi [33] in her comments on Simonton's books. The apparent contradiction, may also be understandable if we reflect on the fundamental differences in conditions: the subjects of short-term experiments are generally normal university students who are not necessarily gifted for graphic-pictorial creativity and not committed in a vital manner, while Simonton studied professional artists of high calibre, working in their specific domain. Moreover, the creativity tests are experimentally applied at the zenith of stress without there being any time for any form of reprocessing of the painful experience, and this differs from the artists' actual experiences in life.

\section{Innovative Classification of Creativity Types: Continuity, Opposition and Detachment}

As regards the problem of evaluating creativity, we must recall here that several tools have been proposed. As far back as the 1960s, Smith [34] listed over thirty different procedures and measures for creativity [35] [36]. However, the critique of the traditional concept of intelligence and thus of classic intelligence tests may be further extended to include, in many cases, the usual reactives of creativity and to the lack of recognition of certain important aspects of creativity itself.

We can start by examining what happened in various eras, and still happens, within the artistic or scientific world. A given style, criterion or fad, in fashion for a certain period, is usually followed by the opposite tendency: for example, abstract art followed figurative art, geometrical art came after informal art, and so on. Artists (or scientists) working in a certain movement prefer to produce works in continuity with the models proposed by their precursors and by the masters they admire. Those artists (or scientists) who instead propose change place themselves in a contrary, alternative, position with respect to what has already been seen or done. Others still prefer to create something "else" completely, that is not connectable to forms of harmonious continuity or to contrary positions with respect to the models concerned.

Another important similarity is seen by taking into account the various relational possibilities between the 
"inducing" substructure and the "induced" one in perceptual structuring processes, such as in illusions of assimilation or contrast, with respect to which we also know circumstances of "neutrality", with a loosening of relational bonds and the absence of reciprocal influences [37] [38].

Going back to the literature on creativity and evaluation trials, we can see how sometimes creativity tests have particularly valorised a sort of creativity which we can call "by assimilation" or "by continuity", and which implies a lower degree of change, innovation and divergence compared to the patterns offered by the examiner. We can see what happens when, following Guilford [3]-[5] or Torrance [39] [40], tasks are assigned such as that of using additional figurative elements to complete an "open" series of circles, stimulating the participant to each time draw a figure which, containing a circle in his pattern, has a different meaning instead: a wheel, the sun, a face, a button etc., as in a well-known protocol also reported by Tyson [41]. In this case, a task is essentially given that assumes the need to constantly respect an already given structure: a circle. Therefore, it is a task which, in some respects, is productive, with a strong aspect of convergence, rather than being a purely creative task, that is less polarised. Different kinds of task could be: drawing an opposite structure to the one given; or drawing a completely different structure. With instructions of the latter kind it is possible to obtain, from highly creative participants, interesting protocols with a high degree of differentiation.

Our work moved in the latter direction in order to devise a new experimental procedure. We proposed using the COD Creativity Test, which evaluates creativity for "Continuity, Opposition and Detachment", and which was developed by Bonaiuto in the 1970s. The COD includes three different and consecutive tasks. In the first one, the subject is given a black pen and a drawing sheet of $35 \times 25 \mathrm{~cm}$. A $3 \mathrm{~cm}$, black-contoured circle appears in the upper left. This first trial resembles the above-mentioned Guilford and Torrance's scales, and is called a "Continuity Creativity Task" here. The subject is given the following written instructions: "Consider this circle as a pattern. You must draw as many figures as possible containing a circle like this; the figures are to be a natural extension of the model circle as much as possible. Concentrate and make some circles which, with the addition of some other element or sign, can communicate a particular meaning. Try to draw as many figures as possible, as long as they incorporate the given model”.

The second sub-test, called "Opposition Creativity Task", uses another sheet of light cardboard similar to the first (with the same circle), and the written instructions are: "Consider this circle as a pattern. Draw as many figures as possible which in some way are shapes opposite to a circle. That is, they must represent the natural opposite of this model. Just concentrate, imagine and draw some figures which, in addition to other elements, have an objective meaning: these new forms should be in contrast to a circle. So, try to draw as many contrasting figures as possible".

The third and last sub-test, called "Detachment Creativity Task", also using the same materials, involves the following written instructions: "Consider this circle as a pattern. Draw as many figures as possible which do not contain either a circle or its opposites. You must draw some figures which have a concrete meaning. But, this time, the figures must be quite different and must have no relation to this model either in terms of continuity or opposition. So these figures will have a concrete meaning, but they will also be something quite different from the original. As in the other cases, draw as many figures as possible”.

These instructions are always typed on a sheet of white paper (A4 size). They are given to each participant, with the drawing materials, in regular succession, as they carry out each task [35] [42].

This graphic and visual test of creativity is evaluated according to the classic parameters of fluency, flexibility, originality, and complexity [5]. Fluency is the quantity of produced figures. Flexibility is the quantity of categories used. Originality is the unique character of the representation. Complexity is the number of details provided. Applying double-blind conditions, three expert examiners rate the creativity level of the subject's productions, first working independently and then as a group to reach a consensus score, giving overall evaluations for each parameters and each participants. More analytical evaluations require great effort for some parameters like originality and complexity, less for fluency and flexibility. The overall evaluation is easier and faster. Each examiner works without knowing the group the subject is assigned to, and provides a personal scale score from 1 to 10 points for each of the four parameters in each drawing. Then, average individual scores are computed for each participant. The resulting scores are available for later statistical processing, comparisons and interpretations.

\section{Theories and Observations on the Effects of Stress or Comfort States}

It is well-known that the experimental literature reports various techniques for obtaining temporary stress or 
relaxation states with Humans. As regards stress, we can firstly mention the assigning of "impossible tasks", a procedure already used by Dembo [43] in order to study some negative emotions and then later applied with some variations by Postman \& Bruner [44]. Different procedures have involved environmental noise [45] [46], exposure to rain, excessive heat or cold; immerging a limb in freezing cold water [47]; prolonged monotonous fixation [37] [38]; isolation and confinement [22] [48]; as well as the opposite condition, i.e. crowding, still in a confined space [49] [50]. Traffic congestion during the rush hour to go to work or get home (commuting traffic) is also considered a stressful factor and accurate systematic observations were conducted by Novaco, Stokols and Milanesi [51], Evans and Carrere [52], Koslowsky and Krausz [53]. Other known techniques consist of projecting slides or short films with an alarming, harsh content [54]-[56]. Various researchers have used situations of hard school examinations [17], doing tasks in front of authoritative examiners [57], intelligence tests with erroneous feedback and in conditions of urgency [58]; performing complex tasks on a computer that is particularly slow in responding [59] [60].

As regards experimental comfort, instead, we can mention procedures envisaging autogenous training and the listening of appropriate musical tunes [19]; the "flotation relaxation" technique [21]-[23]; and various other gradual muscle relaxation procedures, with an imaginative focusing of suitable scenes [58]; some yoga exercises [20]; showing humorous films or handing out a gift consisting of a box of candies [24] [27] [28] [30] [61] [62].

At the end of the eighties our research group developed experimental procedures for studying the influences of emotional and motivational processes activated during stress or during the opposite situation of comfort. The procedures proved able to affect some cognitive processes as well. A short-term experimental stress treatment, that we used in early research on cognitive processes, had participants solving, for 20 minutes, some of the most demanding figures of Raven's Progressive Matrices, with hurried instructions and with false or absent feedback. The alternative experimental treatment of comfort was based on progressive muscular relaxation, also connected with guided imagery, in a quiet darkened setting [58]. Both these procedures were complemented by the evaluation of the reached affective states, through 7-point bipolar Self-Appraisal Scales with adjectives or adjectival sentences of opposite meanings (see examples in Figure 1), applied before each treatment and at its apex. With

Instruction: Take yourself and your situation into consideration as you feel right now. Focus on the feelings that you have at this moment, and only at this moment. Indicate your evaluations by placing a cheakmark in one box only for each pair of opposite adjectives or opposite descriptive phrases. Do this spontaneously and rapidly.

\begin{tabular}{l|l|l|l|l|l|l|l|l}
\multicolumn{7}{c}{3} & \multicolumn{1}{c}{ I Feel I Am } \\
\hline TENSE & & & & & & & & \multicolumn{1}{l}{ RELAXED } \\
\hline AGITATED & & & & & & & & CALM \\
\hline IN CONFLICT & & & & & & & & AT PEACE \\
INTERNALLY & & & & & & & & INTERMALLY \\
\hline WORRIEO & & & & & & & & TRANQUIL \\
\hline ANGRY & & & & & & & & SERENE \\
\hline IRRITATED & & & & & & & & AGREEABLE \\
\hline AGGRESSIVE & & & & & & & & PEACEFUL \\
\hline IMPATIENT & & & & & & & & PATIENT \\
\hline SAD & & & & & & & & HAPPY \\
\hline EMBITTERED & & & & & & & & WELL-DISPOSED \\
\hline DEPRESSED & & & & & & & & EUPHORIC \\
\hline MELANCHOLIC & & & & & & & & JOYFUL \\
\hline
\end{tabular}

Figure 1. Examples from the bipolar self-appraisal scales for exploring changes in emotional and motivational states (source: [64]). 
this tool, we explored a broad emotional area, including anxiety, anger, sadness, embarrassment, shame, guilt and pain, as well as their opposites. We also measured motivations such as aggression, the need for cognitive congruency, curiosity, self-assertion, the need for active body movement, the need for adventure, the need to construct, sociability, sexuality and nutrition demands. Using the same inventory, validated through factor analysis [63] [64]), we also checked some impressions on the self and on the environment, such as feelings of stress, frustration, monotony, threat, insecurity, insufficiency and inferiority, as well as their opposites.

The main effect found as a consequence of the short-term stress treatment was an increment of incongruity intolerance. Also other conflictual aspects became less tolerated: such as ambiguity, uncertainty, complexity. These motivational changes significantly affect some cognitive processes, with increases in the perception of causality and the evaluation of responsibility. The hypothesised psychological mechanism is the increase of intolerance for conflicts, due to conflict overloading during stress, which is followed by a sort of "yearning for explanations"; while the opposite is found with comfort.

Subsequently, we developed a new and more appreciable technique, based on the recollection of personal experiences of real events, depicted through coloured drawings [65] [66]. Here, too, subjects are treated and examined individually. Each person sits at a table with light drawing cardboard $(32 \times 24 \mathrm{~cm})$, a pencil, a pen, 36 coloured pastels and an eraser. The participant is asked to represent his/her individual stressful or relaxed real-life experiences (Figure 2).

In order to obtain stress, the instructions given to the subject are as follows: "Now try to imagine and focus on a personal, particularly stressful, anxiety-arousing, troubling and unpleasant situation. It can be a past experience or a present one that you have felt in this way. Try to represent this experience with the materials here at your disposal. Do it freely, as you are able to, using whatever you wish...”. In the opposite treatment, the subject is asked to recall a particularly relaxing, comfortable and pleasant situation, following instructions in which the other parts are the same. For each treatment, if there is enough time, the subject is asked to imagine and draw another situation of the same type.

The evaluation of the affective states is carried out, as usual in our experiments, through the above-mentioned Self-Appraisal Scales. By comparing data obtained with this inventory and coming from the various experimental groups, it was found that the two techniques - the one based on difficult logical problems, and the new one based on the recollection and drawing procedure-produce very similar affective alterations, which are statistically significant if we examine the pre- and post-treatment score differences. These effects include, under stress, an increase in negative emotions and in aggression, in the need for congruence and for body movement; while under comfort treatments the opposite symmetrical decreases are found. The choice of a drawing-recall technique is based on the ease of administration for a single examiner as well as the nature of the test itself, so that the subjects do not direct their aggressiveness toward the examiner. The stressful procedure does not require active confrontation; on the other hand, it is implies an indirectly induced and relatively passive stress, even though it is quite effective.



Figure 2. Experimental setting for applying the procedure of "Drawing Recall", in order to activate stress or comfort states (source: [65] [66]). 
In the past, to set up this drawing test, we also selected comparison groups characterized only by the pure imaginative and verbal recall of stressful or relaxing situations, or by the reproduction of drawings of stress or comfort provided by other subjects. With these variants, emotional alterations were less evident, often very poor or insignificant [65] [66]. For this reason, the "drawing-recall technique” was definitively preferred.

The contents and the style of the drawings obtained with the main procedure turned out to be very interesting. The analysis of the above-mentioned drawings led to the discovery and definition of a specific graphic pictorial-language, which has been described and studied in detail in some other papers [63] [65] [66]). Under stress, subjects draw a large quantity of straight line figures, angular surfaces, black contours, lack of colour; and even in the case of colour, there is the presence of extreme contrast and the prevalence of dull hues. Subjects prefer a close-up representation, with the tendency to reduce the picture to the centre part of the drawing sheet. Sometimes subjects use an abstract or symbolic style and the drawer is often involved in the drawing. There is movement and activity and the participant frequently uses simplicity and graphic synthesis as well as a hurried execution. There is a permanent representation of conflict. On the other hand, in the case of relaxing situations, the subject mainly uses curved lines, circular surfaces, continuous lines, coloured contours, bright colours, and gradations of colour; a panoramic approach is the most frequent drawing technique; the depictions occupy the whole sheet; frequently, the subject draws static scenes with no representation of movement; the execution is much more complex, full of details and accuracy; situations are often harmonious.

The most frequent content of stress drawings (obtained in Rome and confirmed over several academic years) concerns: congested traffic, car accidents, mourning, family quarrels, conflicts within the couple, difficulties in social relations, heavy sport commitments, difficult examinations and so on. The most frequent situations of comfort include natural landscapes, an outing with one's partner or friends, relaxation in bed, etc. The replication of this kind of investigation with students of the University of California in 1992 gave rise to very similar results [63].

\section{An Empirical Demonstration of the Relevance of Uncertainty and Incongruity Tolerance/Intolerance in Conditioning Creativity Performances}

\subsection{Aims and Hypothesis}

As already mentioned, an overloading of conflict should favour intolerance of incongruity, ambiguity, uncertainty and complexity, since facing strongly incongruous, ambiguous, uncertain, and/or complex configurations means facing additional conflicts. Among the manifestations or consequences of this psychological mechanism, we also expect at least a short-term effect in the field of creativity, in the sense of its prevalent inhibition and stereotyping: because creativity (by definition) has to do with the acceptance of new ideas and figures, even incongruous ones, and the production of strange, unusual and bizarre configurations that challenge and contradict the previous consolidated mental schemata [67].

To verify this hypothesis, we selected an opportune creativity test to be given individually to each subject at the zenith of the treatments of short-term experimental stress. As a comparison trial, we asked subjects of another experimental group - similar to the other group for age, school level, gender composition and social class - to pass through a state of short-term experimental comfort, clearly followed by the same individual creativity test in the same environment.

\subsection{Method}

We chose the technique of the drawing-recall of personal experiences of stressful or relaxing situations, together with the application of Self-Appraisal Scales, as already illustrated in section 3 (Figure 1). The COD Creativity test was applied at the apex of each treatment: each of the three successive tasks lasted seven minutes. In fact, in the original version of this test, there was no time limit for the subject involved in recalling and in drawing immediately after reading each instruction. However, since we wished here to test the effects of short-term experimental stress or comfort on creativity, and because these effects are exposed to decay with the passing of time, we introduced a time limit of 7 minutes for each of the three drawing conditions. Each successive task was assigned immediately after the conclusion of the previous one. Some examples of the productions made by the subjects in the different conditions are presented in Figure 3, Figure 4 and Figure 5.

Results were evaluated (double blindness) by three expert judges on eleven-point scales according to fluency, 

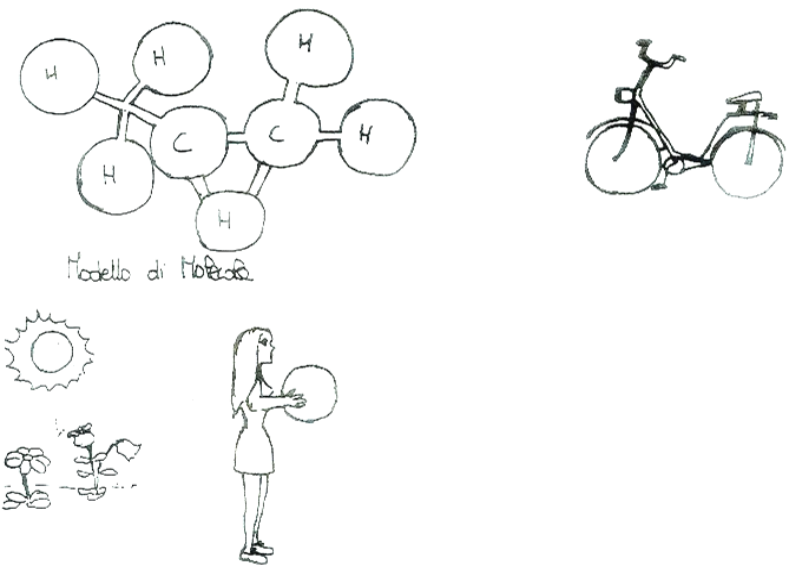

Figure 3. An example of the compilation of the continuity creativity sub-test.
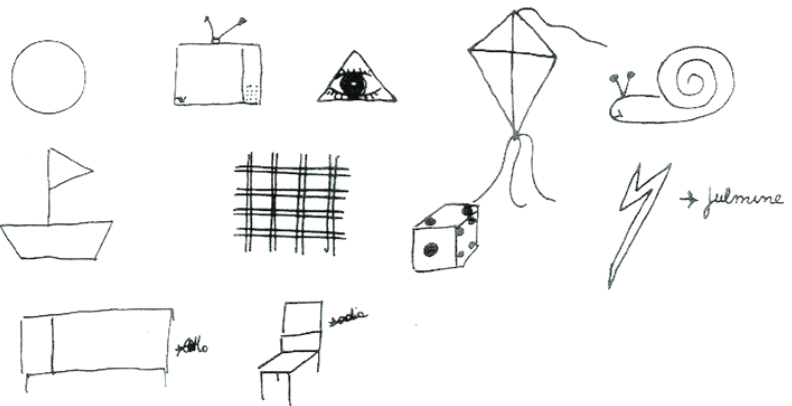

Figure 4. An example of the compilation of the opposition creativity sub-test.

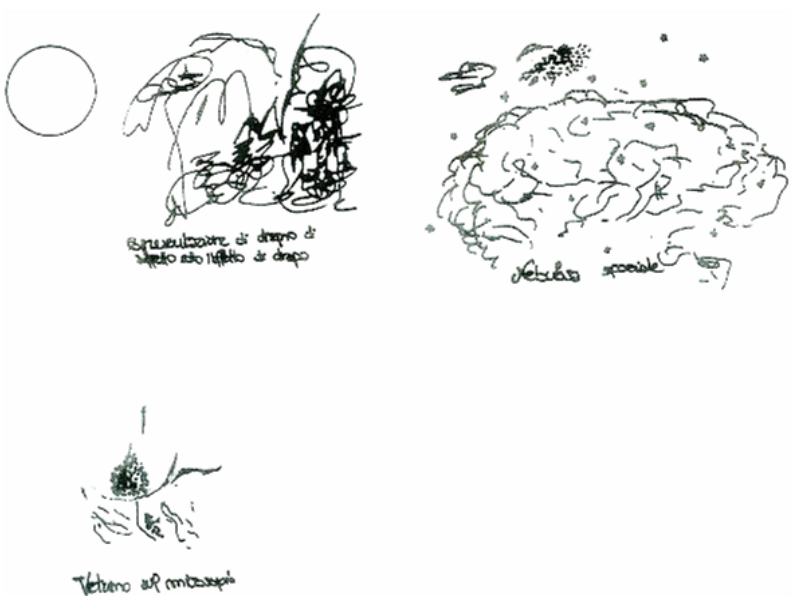

Figure 5. An example of the compilation of the detachment creativity sub-test.

flexibility, originality and complexity classical parameters [5], and computing the partial and overall average scores. Thirty-two individually examined young adults took part in the experiment. They were all university students from 19 to 25 years of age (average age: 22.4), half were women and half men. The participants were divided into two equivalent experimental groups: one undertaking the stress treatment, and the second the comfort treatment. Each participant was individually examined in a quite room with normal lighting (250 lux) at the First University of Rome. The participant sat in front of a grey table $(100 \times 150 \mathrm{~cm}$.) on a padded chair. There 
s/he received the necessary materials to draw her/his own situations of stress or comfort. When the creativity test was given, s/he was asked to sit in front of a second different table so that $\mathrm{s} /$ he could use the new material at the proper time.

\subsection{Results and Discussion}

The statistical analyses revealed that average data reflecting creativity are significantly lower after acute stress with respect to the comfort treatment in almost all the measured parameters or task varieties (Figure 6).

In other words, after this kind of acute stress, in comparison with the opposite condition, the participants significantly exhibited less creativity in almost all parameters measured, according to the Student's t test. We observed, on average, that creative inhibition was indicated by a lack of ideas (see fluency), and especially with few differentiations among them (see flexibility), and with greater stereotyping (see originality) and simplification (see complexity). As a matter of fact, it is meaningful that, after stress treatment, the drawings were generally relatively fewer, not well defined, and often reduced to the essentials. It appeared that most subjects had less imagination and also that they did not want to elaborate even those few ideas by acting in a specific way.

Actually, creative drawings after stress also seem to be produced according to the average graphic language of stress; and creative drawings after comfort are actually representative of the structural and expressive qualities given in the graphic language of comfort. This analogy demonstrates the reliability of these methods, and may be focussed in the conclusive remarks.

As far as the nature of the tests is concerned, significant differences between the effects of the two opposite treatments emerged for Continuity and Detachment, while there were no significant differences for the Opposition sub-test. This can be explained by the fact that even stressed people were able to produce more aggressive ideation, in conformity with the given specific instructions.

Considering the creativity score in relation to the emotional processes activated during the stress or comfort experimental treatments, we noticed some interesting tendencies. Significant negative correlations were found between the overall creativity score and some Self-Appraisal Scales scores, indicating that increases in sadness, anxiety and inferiority feelings after stress correspond to a lower diverging productivity (respectively: $r(30)=$ $-0.43, p<0.05 ; r(30)=-0.35 ; p<0.05 ; r(30)=-0.40, p<0.05)$. That is to say, if during the experimental stress treatment the participant developed such pertinent negative feelings more intensely, then there was a

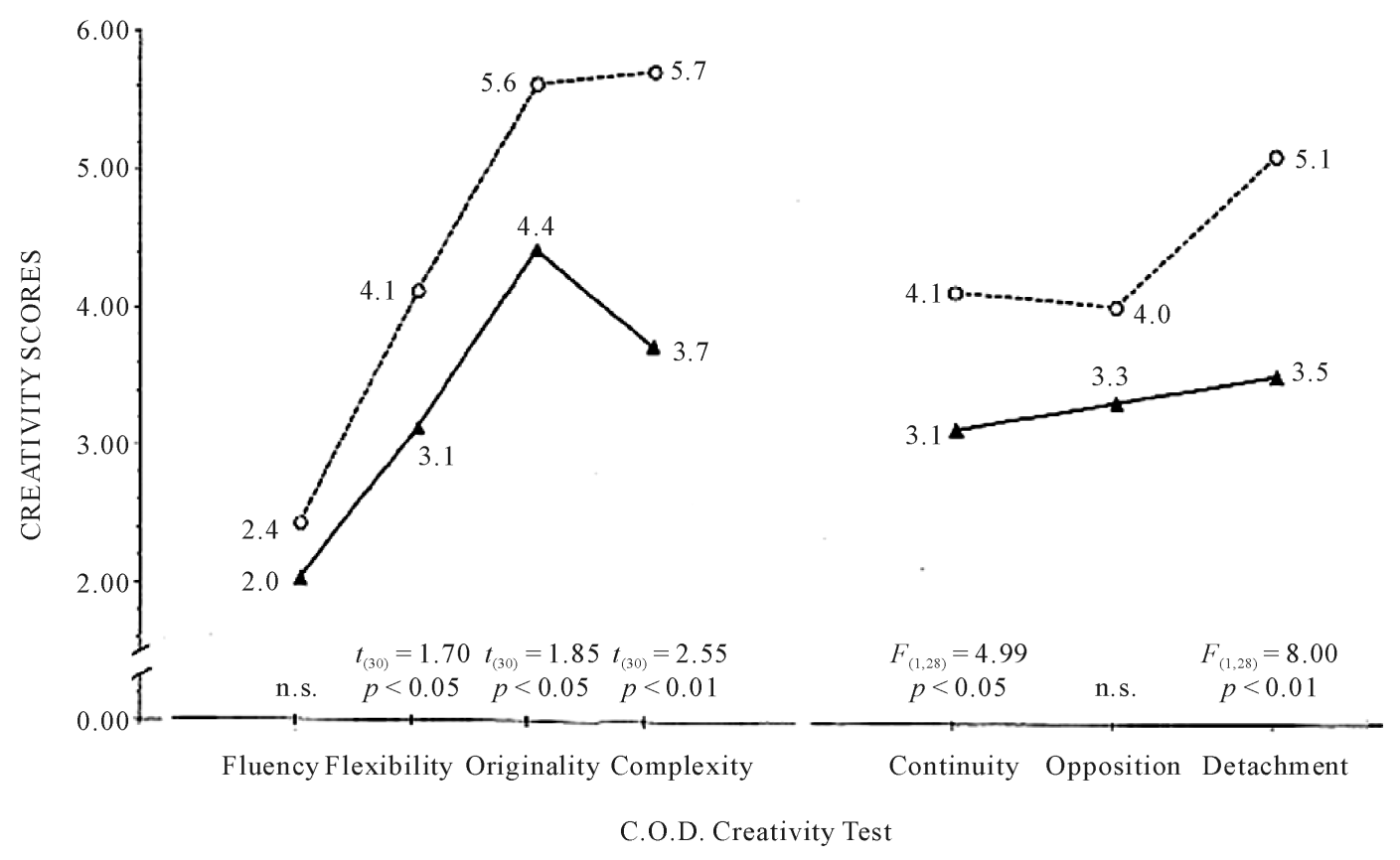

Figure 6. Average creativity scores obtained with the two opposite treatments (stress vs. comfort), considering the four different parameters (fluency, flexibility, originality, complexity), and the three different creativity sub-tests (continuity, opposition, detachment). 
higher inhibition of creativity. However, if the subject felt superior, amused and relaxed, then the effect of stereotyping and inhibition was reduced or at least balanced. With respect to comfort, if the emotional processes generated inferiority, sadness and anxiety, then an intermediate production took place. The highest scores on the creativity tests were reached when the participant developed feelings of superiority, amusement and comfort during the comfort treatment. In other words, a significant negative correlation indicates that an increase in feelings of inferiority, sadness and anxiety during the stress treatment corresponds to a decrease in diverging productivity. A significant negative correlation indicates that an increase in feelings of inferiority, sadness and anxiety corresponded to a decrease in diverging productivity.

As a consequence of these results, the cognitive, decisional and activity processes involved in creativity operations can be considered as strictly reflecting emotional dynamic processes, as well as the experiences gained during the stress or comfort treatments and shown through the specific drawings.

In line with the hypothesis, the results are explained considering the role of conflict overload in acute stress as a factor of incongruity and uncertainty intolerance, generally inhibiting production of bizarre and unusual ideas and configurations, and thus reducing essential aspects relevant to creativity level evaluations, at least for a majority of people. The inverse mechanism (reduction of incongruity intolerance) can explain the opposite effects achieved with comfort.

In this respect, creativity enhancements obtained with flotation relaxation by Suedfeld, Metcalfe and Bluck [21], or by Forgays and Forgays [22] [23], may also be conveniently reinterpreted.

As regards comparisons with other research techniques mentioned in section 3, we should emphasise the greater effectiveness of the "drawing-recall" experimental procedure both for comfort and stress conditions, accompanied by a quick and constant check of the affective states reached (by using the pre- and post-treatment Self-Appraisal Scales).

We have already noted that several experimenters neglected to check whether the stress or relaxation induction techniques they used had actually determined the expected emotional states. By experience, we know that generally in two cases out of every ten the experimental subjects show a resistance to developing the affective states required by the experimenters, so that it becomes necessary to check the actual situation of the independent variable each time: the affective state following the respective treatment. Non checking for these important aspects may have contributed to determining the discrepancies and contradictions in comparisons made between various investigations.

We consider the recognition of short-term changes in incongruity tolerance/intolerance produced by stress and comfort treatments to be important also at an interdisciplinary level, over and beyond the sphere of this study, as an interpretative key and source of forecasts for further theoretical and experimental developments.

Another aspect that may be worth analysing in more detail, to further generalise the conclusions, concerns the opportunity to replicate these studies by using other creativity tests and other procedures to induce stress or comfort states, with respect to the "drawing-recall” technique.

It may also be supposed that recalling emotionally negative experiences may have de-motivating effects when subjects have to draw again in order to fulfil the creativity tasks. Conversely, the drawn recollection of pleasant experiences of comfort could per se have a positive influence on the fact of drawing in creativity tasks. These aspects may hypothetically contribute at least as co-factors, and their weight must be established by replicating the study with stress and comfort treatments over and beyond drawing operations. Even the use of other varieties of creativity (verbal creativity etc) may be useful in answering this question.

Other elements for reflection for developing the experimental procedures may derive from the hypothesis of a curvilinear relation between the intensity of stress and creative performances, as would appear to emerge from the data by Suedfeld and Vernon [68] and partly from the work of Leith [16]. To clarify this point, it may be worth conducting a study including five differentiated experimental groups, in order to compare conditions of severe stress, moderate stress, neutrality, moderate comfort and full comfort. This should allow a better differentiation between linear and curvilinear relations linking affective dynamics to creativity.

From clinical point of view, Ciarrochi, Said and Deane [69] underline that decades of research have generally shown that being more rigid is associated with poorer mental health.

In particular, they hypothesized that the intolerance of uncertainty (IU) was associated with a wide range of indices of poor mental health. They also hypothesized that people high in intolerance of uncertainty would be less resilient in the face of stressful life events.

Results across two cross-sectional surveys supported their hypotheses. Intolerance of uncertainty (IU) was 
associated with more depression, anxiety, stress, suicidal ideation, and hopelessness. In addition, moderational analysis supported the hypothesis that intolerance of uncertainty (IU) magnifies the adversive effect of stressful life events on depression, anxiety and hopelessness. Moreover, intolerance of uncertaintywas more strongly related to the negative indices of well-being than to the positive index of life satisfaction.

Other indications derives from Chen and Hong [70] studies: they give confirmation that the link between stress and uncertainty suggests that intolerance of uncertainty (IU) could augment the negative impact of stressors on anxiety levels.

They examined the interactive effect of intolerance of uncertainty and daily hassles on anxiety symptoms in a non-clinical sample of 110 undergraduates. Findings indicated that intolerance of uncertainty (IU) moderated the relation between daily hassles and residual change in anxiety symptoms over a one-month period, such that daily hassles increased these symptoms among individuals with high intolerance of uncertainty (IU) but not those with low intolerance of uncertainty (IU).

\section{Conclusion}

In summary, data collected show that people who are in a situation of short term experimental stress become intolerant of uncertainty and incongruity and tend to develop mental rigidity, as well as people that are in a condition of permanent stress like happens in clinical samples: this constellation of traits, transitory or permanent, represents a risk factor for mental health.

\section{References}

[1] Guilford, J.P. (1950) Creativity. American Psychologist, 5, 444-454. http://dx.doi.org/10.1037/h0063487

[2] Guilford, J.P. (1956) The Structure of Intellect. Psychological Bulletin, 53, 267-293. http://dx.doi.org/10.1037/h0040755

[3] Guilford, J.P. (1959) Three Faces of Intellect. American Psychologist, 14, 469-479. http://dx.doi.org/10.1037/h0046827

[4] Guilford, J.P. (1959) Traits of Creativity. In: Anderson, H.H., Ed., Creativity and Its Cultivation, Harper \& Row, New York, 142-161.

[5] Guilford, J.P. (1967) The Nature of Human Intelligence. New York, McGraw-Hill.

[6] Guilford, J.P. (1968) Intelligence, Creativity, and Emotional Implications. Knapp, San Diego.

[7] Maddi, S.R. (1964) Motivational Aspects of Creativity. Paper presented at the APA Symposium "Current Issues in Creativity Research”, Los Angeles, CA. Also publ. in Journal of Personality, 33, 331-347.

[8] Hinton, B.L. (1971) Personality factors and resistance to the effects of frustrations on creative problem-solving performance. Journal of Creative Behavior, 5(4), 267-269. http://dx.doi.org/10.1002/j.2162-6057.1971.tb00897.x

[9] Runco, M.A. and Albert, R.I., Eds. (1990) Theories of Creativity. Sage, Newbury Park.

[10] Eysenck, H.J. (1993) Creativity and Personality: Suggestions for a Theory. Psychological Inquiry, 4, 147-178. http://dx.doi.org/10.1207/s15327965pli0403_1

[11] Csikszentmihalyi, M. (1997) Creativity: Flow and the Psychology of Discovery and Invention. Harper Collins, New York.

[12] Falat, M. (1998) Possible Interconnections of the Big Five with Creativity Research. Studia Psychologica, 40, $331-334$.

[13] Falat, M. (2000) Creativity as a Predictor of “Good” Coping? Studia Psychologica, 42, 317-324.

[14] Sternberg, R.J., Ed. (1999) Handbook of Creativity. Cambridge University Press, New York.

[15] Legrenzi, P. (2005) Creatività e innovazione (Creativity and Innovation). Il Mulino, Bologna.

[16] Leith, G. (1972) The Relationships between Intelligence, Personality and Creativity under Two Conditions of Stress. British Journal of Educational Psychology, 42, 240-247. http://dx.doi.org/10.1111/j.2044-8279.1972.tb00717.x

[17] Martindale, C. and Greenough, J. (1973) The Differential Effect of Increased Arousal on Creative and Intellectual Performance. Journal of Genetic Psychology, 123, 329-335. http://dx.doi.org/10.1080/00221325.1973.10532692

[18] Dwral, R.L. (1973) The Influence of Psychological Stress upon Creative Thinking. Polish Psychological Bulletin, 4, 125-129.

[19] Krampen, G. (1997) Promotion of Creativity (Divergent Productions) and Convergent Productions by Systematic Relaxation Exercises: Empirical Evidence from Five Experimental Studies with Children, Young Adults and Elderly. European Journal of Personality, 11, 83-99. 
http://dx.doi.org/10.1002/(SICI)1099-0984(199706)11:2<83::AID-PER280>3.0.CO;2-5

[20] Khasky, A.D. and Smith, I.C. (1999) Stress, Relaxation States and Creativity. Perceptual and Motor Skills, 88, 409416. http://dx.doi.org/10.2466/pms.1999.88.2.409

[21] Suedfeld, P., Metcalfe, J. and Bluck, S. (1987) Enhancement of Scientific Creativity by Flotation REST (Restricted Environmental Stimulation Technique). Journal of Environmental Psychology, 7, 219-231. http://dx.doi.org/10.1016/S0272-4944(87)80031-2

[22] Forgays, D.G. and Forgays, D.K. (1992) Creativity Enhancement through Flotation Isolation. Journal of Environmental Psychology, 12, 329-335. http://dx.doi.org/10.1016/S0272-4944(05)80081-7

[23] Forgays, D.G. and Forgays, D.K. (1992) Flotation Isolation: Anxiety Reducer and Creativity Enhancer. Proceedings of the 13th International STAR Conference, Leuven, 59

[24] Isen, A.M., Dabman, K.A. and Nowicki, G.P. (1987) Positive Affect Facilitates Creative Problem Solving. Journal of Personality and Social Psychology, 52, 1122-1131. http://dx.doi.org/10.1037/0022-3514.52.6.1122

[25] Kaufmann, G. and Vosburg, S.K. (1997) "Paradoxical” Mood Effects on Creative Problem-Solving. Cognition and Emotion, 11, 151-170. http://dx.doi.org/10.1080/026999397379971

[26] Vosburg, S.K. (1998) The Effects of Positive and Negative Mood on Divergent-Thinking Performance. Creativity Research Journal, 11, 165-172. http://dx.doi.org/10.1207/s15326934crj1102_6

[27] Isen, A.M. (1999) On the Relationship between Affect and Creative Problem Solving. In: Russ, S., Ed., Affect, Creative Experience and Psychological Adjustment, Taylor \& Francis, Philadelphia, 3-17.

[28] Isen, A.M. (2004) Some Perspectives on Positive Feelings and Emotions: Positive Affect Facilitates Thinking and Problem Solving. In: Manstead, A.S.R., Frijda, N., Fisher, A., Eds., Feelings and Emotions: The Amsterdam Symposium, Cambridge University Press, New York, 263-281. http://dx.doi.org/10.1017/CBO9780511806582.016

[29] Russell, J.A. (1979) Affective Space Is Bipolar. Journal of Personality and Social Psychology, 37, 345-356. http://dx.doi.org/10.1037/0022-3514.37.3.345

[30] Isen, A.M. and Gorgoglione, J.M. (1983) Some Specific Effects of Four Affect-Induction Procedures. Personality and Social Psychology Bulletin, 9, 136-143. http://dx.doi.org/10.1177/0146167283091019

[31] Duncker, K. (1945) On Problem-Solving. Psychological Monographs, 58, 1-113. http://dx.doi.org/10.1037/h0093599

[32] Simonton, D.K. (1997) Genius and Creativity. Selected Papers, Ablex, Greenwich, CT.

[33] Biasi, V. (1999) Book Review for: D.K. Simonton, Genius \& Creativity. Selected Papers, Ablex, Greenwich, CT, 1997. Rassegna di Psicologia, 16, 170-174.

[34] Smith, R.M. (1968) Characteristics of Creativity Research. Perceptual Motor Skills, 26, 698. http://dx.doi.org/10.2466/pms.1968.26.3.698

[35] Bonaiuto, P. (1970) Indicazioni psicologiche per la didattica delle arti visive (Psychological Indications for Visual Art Education). La Biennale di Venezia, 21, 18-42.

[36] Bartoli, G. (2005) Psicolologia della creatività. Le condotte artistiche e scientifiche (Psychology of Creativity. Artistic and Scientific Performances). Monolite, Rome.

[37] Bonaiuto, P. (1965) Tavola d'inquadramento e di previsione degli "Effetti di campo" e dinamica delle qualità fenomeniche (Table to Frame and Forecast the "Field Effects" and Dynamics of Phenomenal Qualities). Giornale di Psichiatria e Neuropatologia, 93, 1443-1685.

[38] Bonaiuto, P. (1969) Sulle ricerche psicologiche europee in tema di monotonia percettiva e motoria ("Sensory Deprivation” e simili). Il processo della saturazione di qualità fenomeniche [On European Psychological Research regarding Perceptual and Motor Monotony (Sensory Deprivation and the Like). The Process of Saturation of Phenomenal Qualities]. Rassegna Neuropsichiatria, 24, 1-114.

[39] Torrance, E.P. (1966) Torrance Test of Creative Thinking. Directions Manual and Scoring Guide. Personnel Press, Lexington.

[40] Torrance, E.P. (1966) Torrance Test of Creative Thinking. Norms-Technical Manual—Research Edition. Personnel Press, Princeton.

[41] Tyson, M. (1966) Creativity. In: Foss, B.M., Ed., New Horizons in Psychology, Penguin Books, Harmondsworth, 167182.

[42] Bonaiuto, P. (1973) Sviluppo di tecniche di valutazione della creatività attraverso prove di “Continuità”, "Opposizione” e "Distacco" dai modelli (Development of Creativity Evaluation Techniques through Trials of "Continuity”, "Opposition” and "Detachment” from Models). Laboratorio di Psicologia, Università degli Studi di Bologna, Bologna.

[43] Dembo, T. (1931) Der Ärger als dynamisches Problem (Anger as a Dynamic Problem). Psychologische Forschung, 15, 
1-144. http://dx.doi.org/10.1007/BF00406043

[44] Postman, L. and Bruner, J.S. (1948) Perception under Stress. Psychological Review, 55, 314-323. http://dx.doi.org/10.1037/h0058960

[45] Broadbent, D.E. (1971) Decision and Stress. Academic Press, London.

[46] Evans, G.W. and Carrere, S. (1991) Traffic Congestion, Perceived Control, and Psycho-Physiological Stress among Urban Bus Drivers. Journal of Applied Psychology, 76, 658-663. http://dx.doi.org/10.1037/0021-9010.76.5.658

[47] Lang, E. (1993) Personal Communication. Budapest.

[48] Forgays, D.G. and Forgays, D.K. (1992) Individual Differences in the Responses to the Stress of Extreme Isolation. Comunicazioni Scientifiche di Psicologia Generale, 7, 57-70.

[49] Baxter, J.C. and Deanovich, B.S. (1970) Anxiety Arousing Effects of Inappropriate Crowding. Journal of Consulting and Clinical Psychology, 35, 174-178. http://dx.doi.org/10.1037/h0030066

[50] Heimstra, N.H. and McFarling, L.H. (1974) Environmental Psychology. Brooks/Cole, Monterey.

[51] Novaco, R.W., Stokol, D. and Milanesi, L. (1990) Objective and Subjective Dimensions of Travel Impedance as Determinants of Commuting Stress. American Journal of Community Psychology, 18, 231-257. http://dx.doi.org/10.1007/BF00931303

[52] Evans, G.W., Hygge, S. and Bullinger, M. (1995) Chronic Noise and Psychological Stress. Psychological Sciences, 48, 83-92.

[53] Koslowsky, M. and Krausz, M. (1993) On The Relationship between Commuting, Stress Symptoms, and Attitudinal Measures: A LISREL Application. Journal of Applied Behavioral Science, 29, 485-492. http://dx.doi.org/10.1177/0021886393294007

[54] Lefcourt, H.M. and Martin, R.A. (1986) Humor and Life Stress. Antidote to Adversity. Springer, New York. http://dx.doi.org/10.1007/978-1-4612-4900-9

[55] Ancona, L. (1972) L'assetto dinamico della motivazione, il conflitto psichico e i meccanismi di difesa (The Dynamic Organization of Motivation, Psychological Conflict and Defence Mechanisms). In: di Ancona Leonardo (a Cura), Ed., Nuove Questioni di Psicologia, Volume I, La Scuola, Brescia, 887-920.

[56] Palomba, D., Mini, A. and Sarlo, M. (1995) Risposte emozionali a stimuli visivi spiacevoli: Fattori psicofisiologici di mediazione (Emotional Responses to Unpleasant Visual Stimuli: Psychophysiological Mediation Factors). Rivista di Psicologia, 80, 115-116.

[57] Smock, C.D. (1955) The Influence of Psychological Stress on the "Intolerance of Ambiguity". Journal of Abnormal and Social Psychology, 50, 177-182. http://dx.doi.org/10.1037/h0047951

[58] Bonaiuto, P., Biasi, V., Giannini, A.M., Bonaiuto, M. and Bartoli, G. (1992) Stress, Comfort and Self-Appraisal: A Panoramic Investigation of the Dynamics of Cognitive Processes. In: Forgays, D.G., Sosnowski, T. and Wrzesniewski, K., Eds., Anxiety: Recent Developments in Cognitive, Psychophysiologycal and Health Research, Hemisphere, Washington DC, 75-107.

[59] Schleifer, L.M. and Amick, B.C. (1989) System Response Time and Method of Pay: Stress Effects in Computer-Based Tasks. International Journal of Human Computer Interaction, 1, 23-39. http://dx.doi.org/10.1080/10447318909525955

[60] Sherwood, A., Davis, M.R., Dolan, C.A. and Light, K.C. (1992) Cardiovascular Reactivity Assessment: Effects of Choice of Difficulty on Laboratory Task Responses. International Journal of Psychophysiology, 12, 87-94. http://dx.doi.org/10.1016/0167-8760(92)90046-E

[61] Isen, A.M., Johnson, M.M.S., Mertz, E. and Robinson, G.F. (1985) The Influence of Positive Affect on the Unusualness of Word Associations. Journal of Personality and Social Psychology, 48, 1412-1426. http://dx.doi.org/10.1037/0022-3514.48.6.1413

[62] Locher, P. (2006) Viewers' Verbal Reactions to Art: An Essential Component of Experimental Aesthetic Research. In: Gottesdiener, H. and Vilatte, J.-C., Eds., Culture and Communication, IAEA, Avignon, 19-24.

[63] Bonaiuto, P., Giannini, A.M. and Biasi, V. (2003) Perception Theories and the Environmental Experience. In: Bonnes, M., Lee, T. and Bonaiuto, M., Eds., Psychological Theories for Environmental Issues, Ashgate, Aldershot, 95-136.

[64] Biasi, V., Bonaiuto, P. and Giannini, A.M. (2010) Measures of Emotional and Motivational Processes Activated by Stress or Comfort Conditions. Key Engineering Materials, 437, 540-544. http://dx.doi.org/10.4028/www.scientific.net/KEM.437.540

[65] Biasi, V. and Bonaiuto, P. (1997) Color and the Experimental Representation of Stress and Comfort. In: Sivik, L., Ed., Color and Psychology, Scandinavian Color Institute, Stockholm, 59-65.

[66] Biasi, V. and Bonaiuto, P. (1997) Aesthetic Level of Drawings Made under Conditions of Emotional Activation. In: Dorfman, L., Martindale, C., Leontiev, D., Cuphick, G., Petrov, V. and Machotka, P., Eds., Emotion, Creativity and Art, Volume 1, Perm State Institute of Arts \& Culture, Perm, 319-348. 
[67] Biasi, V., Chiappetta Cajola, L. and Bonaiuto, P. (2010) Valutare la formazione degli schemi mentali nei disturbi dell'apprendimento (Evaluating the Formation of Mental Schemata in Learning Disorders). Journal of Educational, Cultural and Psychological Studies, 2, 117-138.

[68] Suedfeld, P. and Vernon, J. (1965) Stress and Verbal Originality in Sensory Deprivation. Psychological Record, 15, 567-570.

[69] Ciarrochi, J., Said, T. and Deane, F.P. (2005) When Simplifying Life Is Not So Bad: The Link between Rigidity, Stressful Life Events, and Mental Health in an Undergraduate Population. British Journal of Guidance \& Counseling, 33, 185-197. http://dx.doi.org/10.1080/03069880500132540

[70] Chen, C.Y. and Hong, R.Y. (2010) Intolerance of Uncertainty Moderates the Relation between Negative Life Events and Anxiety. Personality and Individual Differences, 49, 49-53. http://dx.doi.org/10.1016/j.paid.2010.03.006 
Scientific Research Publishing (SCIRP) is one of the largest Open Access journal publishers. It is currently publishing more than 200 open access, online, peer-reviewed journals covering a wide range of academic disciplines. SCIRP serves the worldwide academic communities and contributes to the progress and application of science with its publication.

Other selected journals from SCIRP are listed as below. Submit your manuscript to us via either submit@scirp.org or Online Submission Portal.
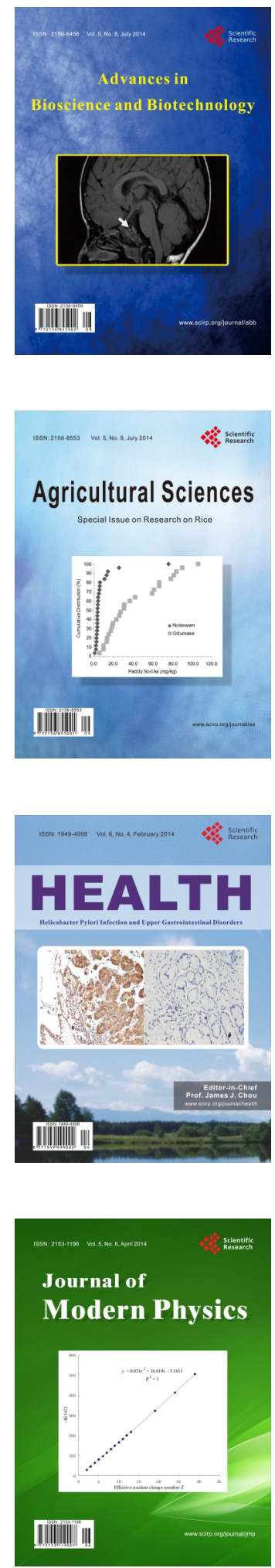
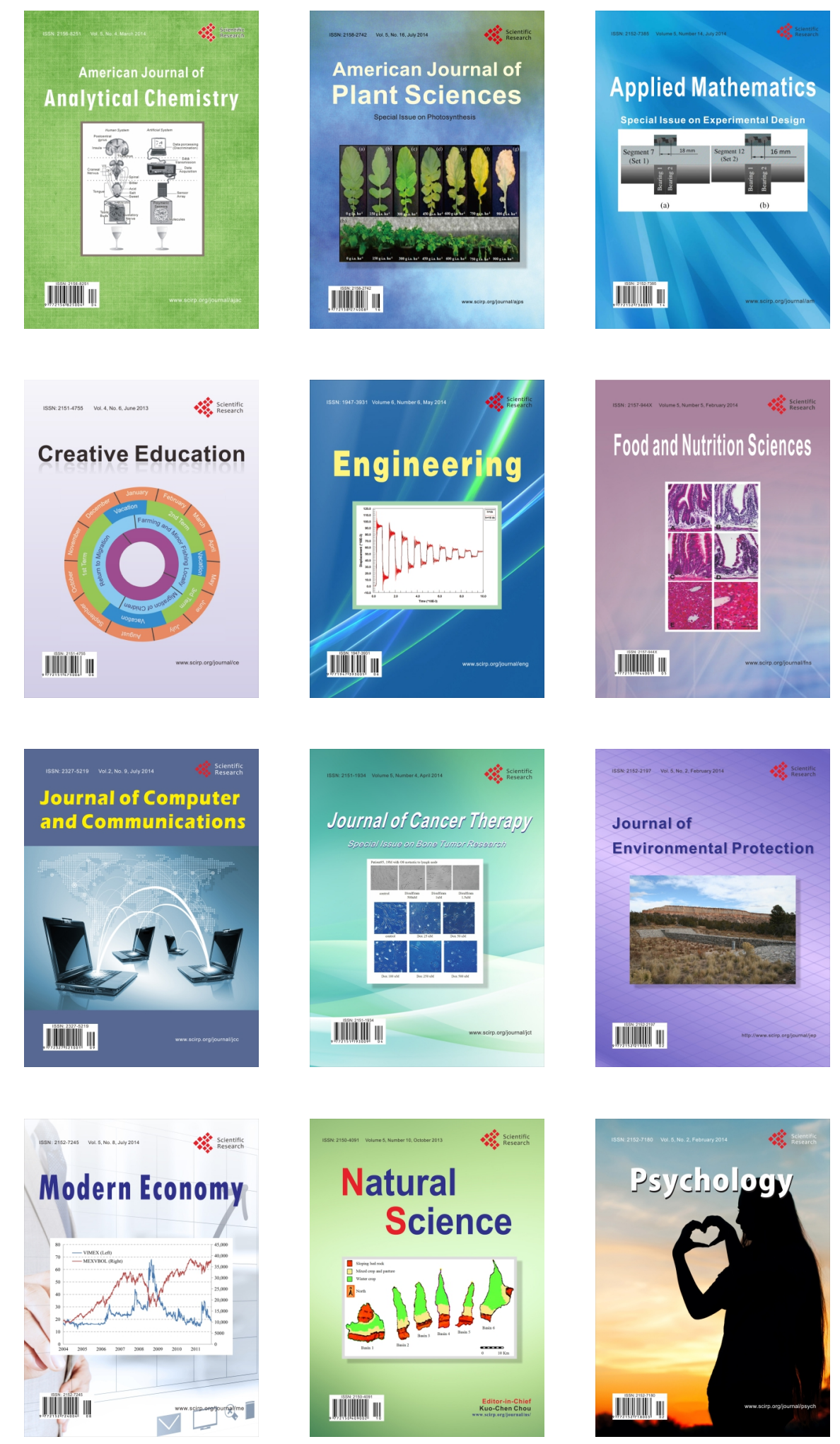